ISSN: 2238-8052

\title{
SÍMBOLOS MUNICIPAIS DE BARREIRAS (BAHIA, BRASIL): REPRESENTAÇÕES DO TERRITÓRIO NO LIMITE ENTRE IDENTIDADE E PODER
}

\author{
MUNICIPAL SYMBOLS FROM BARREIRAS (BAHIA, BRAZIL): REPRESENTATIONS OF TERRITORY \\ ON THE BORDER BEETWEEN IDENTITY AND POWER
}
SÍMBOLOS MUNICIPALES DE BARREIRAS (BAHIA, BRASIL): REPRESENTACIONES DEL TERRITORIO EN EL LÍMITE ENTRE IDENTIDAD Y PODER

Paulo Roberto Baqueiro BRANDÃO1

Artigo recebido em 03/05/2018 e aceito em 05/07/2018

Palavras-chave: Representações territoriais; Símbolos municipais; Barreiras (Bahia, Brasil)

Keywords:

Territorial representations; Municipal symbols; Barreiras (Bahia, Brazil)

\section{Resumen:}

Representaciones territoriales; Símbolos municipales; Barreiras (Bahia, Brasil).

\section{R E S U M O}

Os símbolos oficiais de um município - bandeira, brasão e hino - são representações sintéticas de uma identidade e das relações de poder que, ao longo da história, são conduzidos, de forma efetiva ou como intenção, pelos agentes locais na construção do território que lhes cabe representar. A leitura sistemática, crítica e reflexiva de tais símbolos e dos seus elementos constitutivos, pode gerar uma interpretação das formas de representação ali contidas. Além disso, há que se buscar compreender as concepções de território que dois dos três símbolos citados - brasão e bandeira - carregam, evidenciando, assim, as intencionalidades que vigem no limite entre identidade e poder, neste caso, tratando do município de Barreiras (Bahia, Brasil), concebido por suas elites como a "capital do agronegócio" e escolhido para esta análise como parte de um contexto mais amplo de pesquisas de cunho geográfico-histórico sobre a dita localidade.

\begin{abstract}
A B S T R A C T
The official symbols of a municipality - its flag, coats of arms and anthem - are synthetic representations of an identity and power relations that throughout history are lead in an effective way or as an intention, by local agents who set up the territory that it is up to them to represent. The systematic, critical and reflective reading of such symbols and their constituent elements can generate an interpretation of the types of representation therein. In addition, it is necessary to seek to understand the conceptions of territory that two out of the three mentioned symbols - coat and flag - carry, thus evidencing the intentionalities that exist in the border between identity and power, especially in the case of the municipality of Barreiras (Bahia, Brazil), conceived by its Elites as the "agribusiness capital" and chosen for this analysis as part of a broader context of geographic-historical research on this locality.
\end{abstract}

\section{R E S U M E N}

Los símbolos oficiales de un município - bandera, escudo e himno - son representaciones sintéticas de una identidad y de las relaciones de poder que, a lo largo de la historia, son conducidos, de forma efectiva o intencionalmente, por los agentes locales en la construcción del território que les compete representar. La lectura sistemática, crítica y reflexiva de tales símbolos y de sus elementos constitutivos puede generar una interpretación de las formas de representación allí contenidas. Además de

\footnotetext{
${ }^{1}$ Universidade Federal do Oeste da Bahia. Grupo de Pesquisa Dinâmicas Espaciais e Desenvolvimento Territorial. E-mail: paulo.baqueiro@ufob.edu.br.
} 
eso, se busca comprender las concepciones de território que dos de los tres símbolos bandera y escudo - cargan, evidenciando, así, las intencionalidades que están vigentes en el límite entre identidad y poder, en este caso tratándose del municipio de Barreiras (Bahia, Brasil), concebido por sus elites como la "capital de los agronegócios" y elegida para este analisis como parte de un contexto más amplio de investigaciones de caracter geográfico-histórico sobre dicha localidade.

\section{INTRODUÇÃO}

A partir da vigência da atual Constituição nacional, promulgada em 1988, o município passou a ser considerado, em paridade com a União e os Estados, parte da tríade de entes federativos do Brasil, tendo garantida, assim, autonomia administrativa, política, normativa e financeira. Por tal condição, a exemplo do que ocorre com os demais entes da Federação, a essa unidade políticoadministrativa brasileira é permitido possuir símbolos oficiais, quais sejam: bandeira, brasão e hino.

Tais elementos servem para apresentar, de forma sintética, as características físicoambientais, culturais, históricas, políticas e/ou econômicas que, para os agentes locais, mereçam ser reveladas como características mais importantes do município, expondo, consequentemente, representações do território, com os respectivos aspectos identitários e relações de poder que são acionados quando da elaboração dos versos e imagens que compõem os ditos símbolos.

O que se pretende, neste escrito, é buscar compreender as concepções de território que dois desses símbolos citados - brasão e bandeira - carregam, evidenciando, assim, as intencionalidades que vigem no limite entre identidade e poder, principalmente em se tratando do município de Barreiras, localizado nos cerrados baianos, e até bem pouco tempo concebido por suas elites como a «capital do agronegócio».

\section{OS SÍMBOLOS OFICIAIS E O SEU CONTEÚDO TERRITORIAL}

Assim como os seus pares federativos, ou seja, a União e os Estados, os municípios brasileiros possuem símbolos que os representam. Brasão, bandeira e hino formam um conjunto de representações de uma municipalidade, para os quais se atribuem finalidades e usos próprios, vinculados, na maioria das vezes, a identificação formal da unidade político-administrativa representada.

Vale, aqui, uma breve explicação sobre os motivos pelos quais, nesta análise, o hino municipal de Barreiras foi excluído: (a) além de ser um símbolo pouco conhecido/apropriado pelos munícipes, na medida em que seja rara a sua execução em atos oficiais (ao contrário dos demais símbolos, amplamente utilizados), sendo, portanto, menos presente no cotidiano dos cidadãos locais, (b) possui uma letra que exalta de modo mais acentuado os atributos físico-ambientais do município, temática cuja assimilação, para efeito de um exame da relação identidade, território e poder, é menos evidente. 
Ao retomar a análise, é fundamental salientar que todos esses símbolos são produzidos sob lógicas formais, seguem normas rígidas de elaboração e possuem, inclusive, campos de estudos sistemáticos próprios. Neste escrito, são de interesse os vínculos da Geografia com dois desses campos disciplinares, quais sejam: Heráldica e Vexilologia.

Sobre a Heráldica, Berg (2015) afirma que tal conhecimento pode ser considerado como a ciência, arte e estudo dos brasões. Para Serrão (citado por NOGUEIRA, 2012, p. 25), fazendo uso de uma concepção que pode ser mais facilmente assimilável por um geógrafo, "a heráldica (...) é uma ciência e uma arte que estuda, ordena e elabora os símbolos ou 'marcas' da personalidade singular ou colectiva, moral ou territorial".

A Vexilologia, por sua vez, é, segundo a Sociedad Española de Vexilología, em obra coordenada por Álvarez (2003, p. 174), o termo designativo da "Ciencia que estudia las insignias, enseñas, banderas, etc. (...). El nombre deriva de la palavra latina vexillum-i, que en una de sus acepciones significa cortina y en otra significa «bandera propia de la caballería romana".

Embora não seja aparente à primeira vista, há, tanto na Heráldica quanto na Vexilologia, um conteúdo geográfico a ser explorado, notadamente naquilo que diz respeito aos aspectos territoriais que um brasão e/ou uma bandeira representam. Para Berg $(2009$, p. 76), os símbolos vexilológicos e heráldicos carregam significados e se configuram como "instrumentos por excelência de integração social", sendo vetores, portanto, de valoração de fatos, objetos, pessoas e, vale acrescentar, territórios.

Ademais, bandeiras e brasões são elementos que contribuem significativamente na construção de identidades, pois projetam uma mensagem, "que é propositalmente e meticulosamente construída" (BERG, 2012, p. 313), contribuindo também para mascarar as diferenças, ao tempo em que forjam um sentido de grupo.

Além disso, tratando especificamente da relação entre tais símbolos e a Geografia, Berg (2009, p. 77-78) afirma: “Um símbolo condensa e expande sentidos, sentidos estes que podem estar ligados a um determinado espaço geográfico, cujas características únicas, ou seja, seu contexto, o torna signo e lugar (...) de diferenciação de outros espaços”.

Fica claro que os símbolos acabam sendo acionados como elementos de construção de uma retórica do território, fazendo chegar à coletividade uma mensagem referente à identidade (real ou pretendida) do espaço que se quer representar.

Em se tratando da relação entre Geografia e Vexilologia, Berg (2012, p. 312) afirma, de início, que "Uma bandeira não se restringe apenas a um pedaço de pano que tremula ao vento; suas cores, formas, divisões e iconografia têm um sentido de ser". Apesar de reconhecer que as bandeiras não sejam objetos geográficos de per se, para o autor, há um conjunto de referências projetado por tais símbolos que desvela o conteúdo geográfico do espaço representado. 
No que concerne especificamente à convergência de interesses entre Geografia e Heráldica, Théry (2013) identifica o fato dos brasões serem empregados até os dias atuais para representar identidades territoriais e a possibilidade da utilização, pelo geógrafo, da precisa e rigorosa linguagem desses símbolos na descrição sintética de configurações territoriais que são apresentadas em mapas e gráficos como relações possíveis de se estabelecer entre os ditos campos do conhecimento.

Berg (2015, p. 124), por sua vez, aponta a existência de três ramos principais da Heráldica, quais sejam: a heráldica de família, que trata dos brasões de nobres, aristocratas e suas linhagens; a heráldica eclesiástica, que estuda os brasões de membros da Igreja; e a heráldica de domínio, de maior interesse para a Geografia,

(...) pois aborda os brasões de entidades territoriais e seus atributos característicos, como os acidentes geográficos (rios, lagos, mares, montanhas, montes, promontórios, enseadas, etc.), plantas e animais típicos, a produção agrícola e industrial, além de monumentos e personagens históricos que dão memória aos lugares, bem como lendas, mitos e demais associações com a toponímia, fundação ou origens.

Fica evidente, pois, a possibilidade de construir pontes entre a ciência geográfica e os saberes vexilológico e heráldico. No caso em tela, pretende-se estabelecer esse diálogo a partir da busca pela interpretação daquilo que as bandeiras e brasões assimilam dos territórios representados, bem como pela compreensão do papel territorializador exercido pelos agentes quando da escolha dos elementos a serem ressaltados ou, em sentido oposto, excluídos de tais símbolos.

Para tanto, há que se considerar que, uma vez que se escolha tratar do tema por meio de uma abordagem territorial, é fundamental que se dê ênfase tanto ao viés identitário e material relativos às relações de poder que envolvem a elaboração dos símbolos, afinal, as bandeiras e brasões existem, também, para uma dupla função: promover coesão do grupo representado e exaltar o poder que os setores hegemônicos integrantes desse mesmo grupo têm em se fazerem representar.

Como instância espacial de poder, o território é locus de relações sociais cuja razão de ser mais proeminente é a tentativa ou efetivação da dominação e/ou apropriação do espaço por um determinado indivíduo, grupo ou entidade sobre os demais. A esses se lhe denominam agentes.

Ademais, em meio aos estudiosos da abordagem territorial, muitos concordam - cada um ao seu modo - que o território é, concomitantemente, "funcional e simbólico" (HAESBAERT, 2008, p. 21), "modelagem material" e "relação social" (SOUZA, 2009, p. 66), e "material e imaterial" (SAQUET, 2009, p. 87). Em suma, os raciocínios dos autores convergem para uma concepção do território como um amalgama de elementos racionais e subjetivos e de elementos concretos e relacionais.

Segundo Paasi (2003), um dos elementos cruciais para a formação de um território é a criação de formas simbólicas, o que inclui bandeiras, brasões e estátuas. Em outras palavras, por sua eficiência discursiva em favor de uma comunhão coletiva, bandeiras, brasões ou mesmo os hinos são elementos cujo propósito, além de identificar aqueles que constituem um determinado grupo e os de 
fora dele, é diluir desigualdades e diferenças, apaziguar dissensos e conflitos, incitando, por meio da sua capacidade - ao menos em teoria - de representar a todos, a criação de uma áurea de homogeneidade ou, em outros termos, uma identidade coletiva.

Mas a quem cabe escolher as cores, formas, figuras, enfim, os elementos representativos de um território? Quem define quais elementos naturais, construções humanas, aspectos econômicos ou valores culturais devam compor um símbolo oficial de um país, estado ou município? Sob que tipo de «inspiração» o fazem? Para este autor, é justamente na resposta a tais perguntas que o debate sobre o conteúdo territorial dos símbolos oficiais se estabelece, como se verá a seguir, por meio do exame do caso barreirense.

\section{BARREIRAS, “CAPITAL DO AGRONEGÓCIO”}

Maior e mais importante município do Oeste Baiano, Barreiras (Figura 1) é, atualmente, a morada de cerca de 160 mil habitantes. Embora sua origem remonte ao segundo decênio do século XIX e a emancipação em relação ao hoje vizinho Angical tenha ocorrido já em 1891, o período de maior dinâmica econômica e demográfica do município ocorreu entre os anos finais da década de 1970 e 2000, quando, graças ao processo de reestruturação produtiva do território presidido por atividades de caráter agroexportador, houve grande afluxo de bens, capital e população (BRANDÃO, 2012).

Figura 1. Localização do município de Barreiras (Bahia, Brasil).

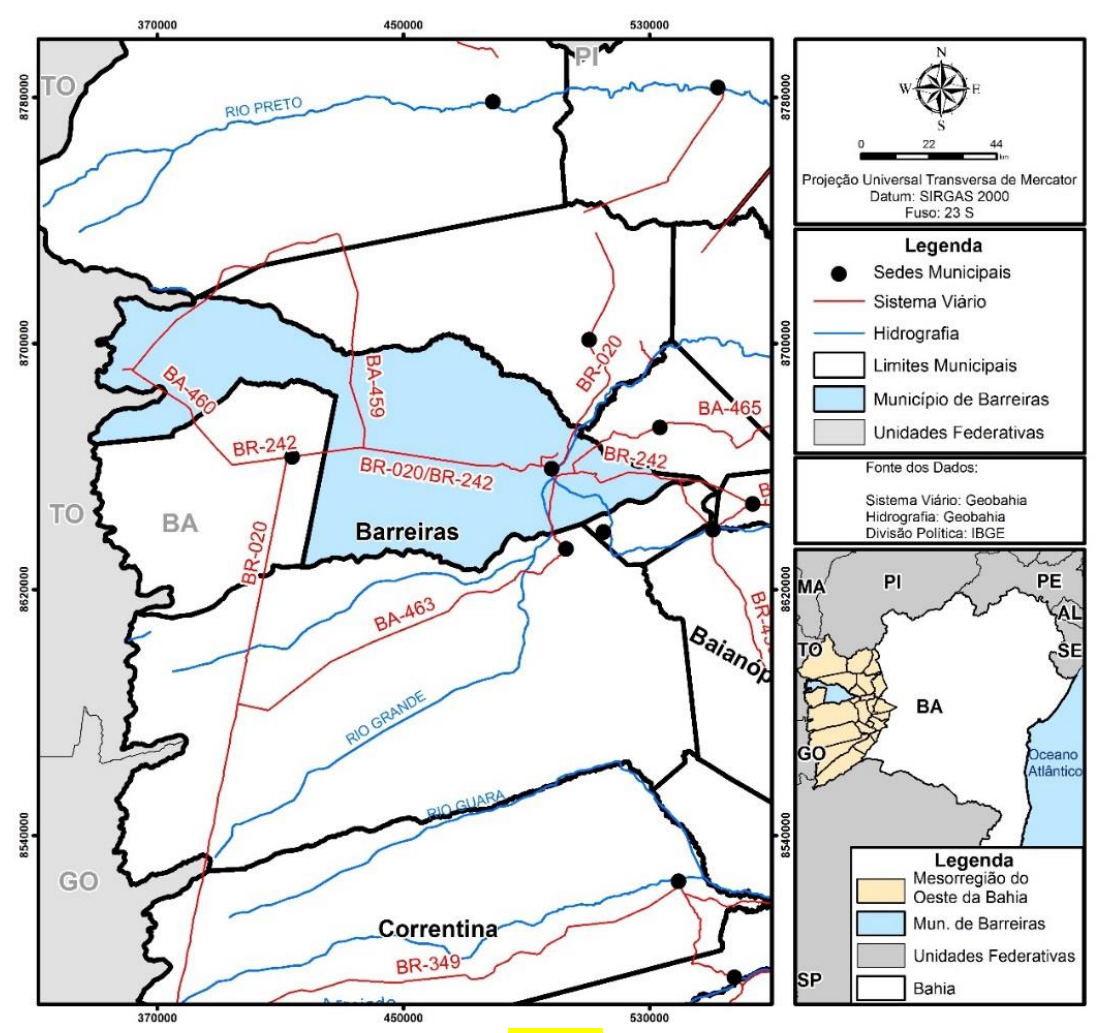

Fonte: 
Barreiras é um dentre os muitos casos de municípios localizados em regiões consideradas preferenciais para a intensificação das relações capitalistas por meio da criação de sistemas agroindustriais altamente tecnicizados, onde formam-se arranjos territoriais de produção agrícola (Elias, 2006) cujos agentes passam a impor uma lógica de organização que incide diretamente na aceleração do processo de urbanização.

Segundo Elias (2006, p. 234), como resultado do aumento da terciarização nas urbes vizinhas às áreas da agricultura modernizada, há

(...) uma grande metamorfose e crescimento da economia urbana das cidades próximas das produções agropecuárias modernas, paralelamente ao desenvolvimento de um novo patamar das relações entre cidade e campo, vislumbrável nos diferentes circuitos espaciais de produção e círculos de cooperação estabelecidos entre esses dois espaços. 0 crescimento da produção não-material se deve ainda ao crescimento populacional e à revolução do consumo, esta última erigida sob os auspícios do consumo de massa, que impõe numerosas necessidades associadas à existência individual e familiar.

Em um primeiro momento (final da década de 1970 e início da seguinte), as condições favoráveis à implantação de uma nova frente de expansão agrícola no Oeste Baiano atraíram agricultores - oriundos, em sua maioria, dos estados do Sul do Brasil - para a região mais ocidental do município, conhecida como Gerais, onde passaram a se concentrar as lavouras. Contudo, na etapa posterior (entre os anos 1980 e 1990), seja pelas exigências crescentes de atividades e profissionais para dar suporte às formas de reprodução social e econômica tornadas cada vez mais complexas ou pela opção ao absenteísmo como modo de vida, o município de Barreiras e o distrito de Mimoso do Oeste (atual Luís Eduardo Magalhães) passaram por vertiginosos processos de urbanização.

No período, o agronegócio passou a presidir o processo de reestruturação territorial produtiva nas escalas municipal e urbana de Barreiras. Devido à demanda por sistemas de engenharia (SANTOS, 1994), força de trabalho especializada e serviços de apoio, muitos destes prenhes em tecnologia, os responsáveis pelo desenvolvimento da atividade agrícola de alto rendimento - o Estado e os agentes econômicos - forjaram territórios mais fluídos às operações corporativas. Decorre disso, por exemplo, a titulatura de "capital do agronegócio", que se atribuía até recentemente à cidade-sede de Barreiras (atualmente, tal designativo é conferido a Luís Eduardo Magalhães).

Nas palavras de Souza, et al. (2015, p. 96):

Assim, Barreiras que já figurava como centro do terciário em âmbito regional, graças ao papel de entreposto de fluxos comerciais advindos pela via fluvial e por caminhos terrestres, passou a ser dimensionado também como um importante polo agroindustrial no estado da Bahia (antes da criação do município de Luís Eduardo Magalhães), tendo se transformado em um espaço luminoso, inserido no circuito econômico mundial, com a instalação de grandes multinacionais cuja produção de soja está voltada para a exportação.

Nesse contexto de crescente complexificação das relações sociais, econômicas e políticas, alguns agentes consolidaram a sua participação histórica, enquanto outros, até então inexpressivo ou 
mesmo inexistentes, passaram a ter papel preponderante na dinâmica territorial do município de Barreiras.

Dentre os diversos agentes, há que se destacar os agricultores oriundos dos estados mais meridionais do Brasil, que contribuíram de modo decisivo na recriação de uma identidade barreirense fortemente assentada em mitos fundadores relacionados aos pretensos «pioneiros», autoreivindicantes do papel de desbravadores do Oeste, e, ao mesmo tempo, de introdutores do desenvolvimento no município de Barreiras e em toda a região.

Segundo Rodrigues e Ferreira (2009), as transformações produtivas no campo se estruturaram como parte de um contexto que envolve a introdução de novas técnicas agrícolas, as finalidades políticas e as relações entre o produtor e os recursos naturais. Tais fatores tornam menos necessária a presença contínua do homem no campo, criando uma população absenteísta que passa a influenciar a cidade próxima às áreas de produção em seu aspecto demográfico, mas também, vale mencionar, como um agente com força política.

O caso de Barreiras converge com o exposto anteriormente, levando-se em conta que, diante de tal quadro, criou-se todo um ambiente favorável à atuação/influência hegemônica de tal agente, que incide em diversos aspectos da vida econômica, política e social locais, o que inclui a escolha dos elementos que figuram nos símbolos oficiais da municipalidade.

\section{OS SÍMBOLOS MUNICIPAIS BARREIRENSES NO LIMITE ENTRE IDENTIDADE E PODER}

Assim como ocorre na grande maioria dos municípios brasileiros, Barreiras possui três símbolos oficiais, ou seja, hino, brasão de armas e bandeira (BARREIRAS, 2015), os dois últimos tendo sido criados no início da década de 1990 e escolhidos por meio de concurso promovido pela Câmara de Vereadores, conforme noticiado em matéria do Jornal Nova Fronteira (1991). De acordo com o que já se afirmou alhures, no âmbito deste estudo, a análise está focada nos dois últimos mencionados (Figura 2).

Figura 2. Brasão de armas e bandeira do município de Barreiras (Bahia, Brasil).
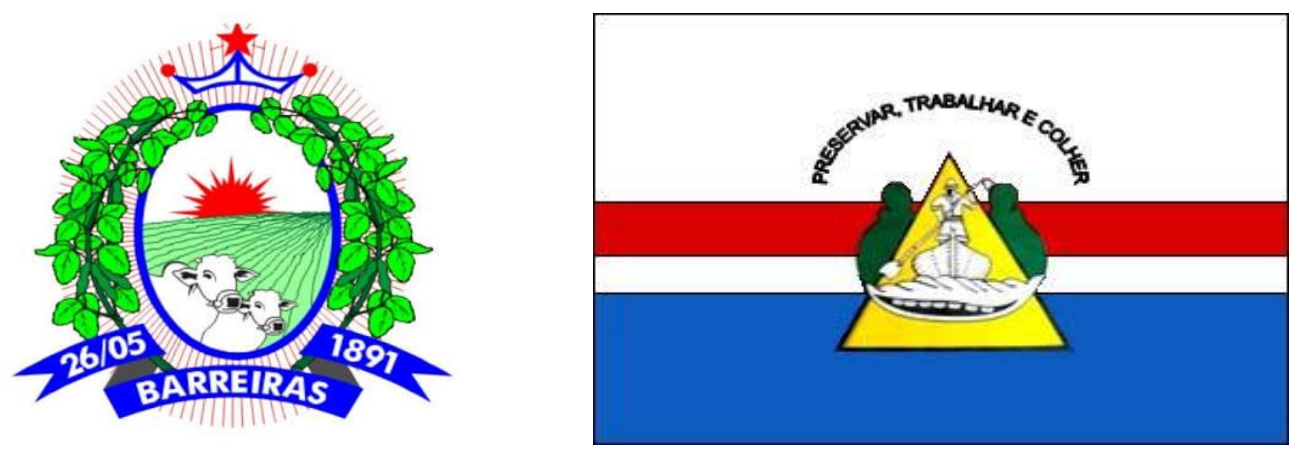

Fonte: 
O brasão de Barreiras possui uma forma oval, sem partições, contendo a imagem de um par de bovinos à frente de uma lavoura e, em último plano, o sol poente. Tal imagem é ladeada por dois ramos de soja frutificados, estando encimada por uma coroa estilizada e sobre uma faixa com os dizeres que aludem à data de emancipação e ao topônimo do município. Todo o conjunto está sobre um resplendor de raios em goles, cujo contorno tem, também, uma forma oval.

Quanto à bandeira municipal, é de autoria do artista plástico barreirense conhecido como Randesmar. Suas características são descritas de modo extremamente simplificado na Lei Orgânica do Município (BARREIRAS, 2015, p. 4): "Nas cores vermelha, azul e branca, numa alusão à bandeira da Bahia, no centro da bandeira um triângulo amarelo que traz a figura de um grão de soja e um barco com um pescador. Acima da figura o lema: PRESERVAR, TRABALHAR E COLHER".

De um ponto de vista da técnica e nomenclatura vexilológicas, pode-se afirmar que a bandeira oficial barreirense possui a forma mais comum existente, ou seja, retangular, com proporções de 2:3 (duas unidades de largura por três unidades de comprimento). Suas cores predominantes são o branco e o azul, horizontalmente dispostos como campo, sendo que a primeira ocupa $2 / 3$ de área e está separada por uma orla vermelha divisando o meio da bandeira. No centro, leva um emblema triangular, em amarelo, com uma vagem de soja e um pescador sobre uma pequena embarcação, encimadas pelo lema "Preservar, Trabalhar e Colher" em arco.

Em ambos os símbolos, é possível observar a existência concomitante de elementos que, por um lado, denotam referenciais identitários do município, posto que representem formas tradicionais de reprodução social e econômica (pequena agricultura, pecuária extensiva e pesca artesanal), e, por outra parte, expõem a presença daqueles que reportam relações de poder, estando ligados aos fatores da reestruturação territorial produtiva que se deu em Barreiras e, por extensão, aos interesses dos seus agentes.

No brasão de armas, o gado bovino, elemento recorrente naquelas imagens que, em geral, simbolizam a cultura sertaneja, aparece como representação da pecuária extensiva, uma das formas de reprodução econômica mais tradicionais em toda a parcela territorial da Bahia à esquerda do Rio São Francisco há séculos, o que inclui o atual município de Barreiras.

Geraldo Rocha (2004, p. 18), em carta endereçada ao presidente Getúlio Vargas, afirmava: “A bacia do São Francisco foi, desde os tempos coloniais, uma região dedicada à indústria pastoril”. De fato, conforme corroborado por Santos Filho (1989), a pecuária foi introduzida na região ainda em princípios do período colonial e manteve-se como uma das principais atividades econômicas até a segunda metade do século XX, quando da ascensão da agricultura de alto rendimento.

Contudo, é importante salientar que, a despeito da importância que lhe é devida, seja na constituição de uma economia de escala ou como contribuinte na formação de uma cultura sertaneja em Barreiras, a pecuária não é a única atividade historicamente desenvolvida no município. É possível 
apontar como atividades em paridade de importância a produção da cana-de-açúcar e seus derivados, algodão, borracha da mangabeira, comércio, entre outras, todas negligenciadas no brasão municipal.

A pretensa integração dos elementos já mencionados - o gado e a lavoura - propõe uma relação harmoniosa entre os subespaços que dividem o município de Barreiras desde um ponto de vista geoeconômico, ou seja, os «Gerais», a oeste, onde vige a agricultura de alto rendimento, e o "Vale", a leste, que vem a ser o locus de permanência de formas tradicionais/arcaicas de produção agropastoril.

Em se tratando da bandeira, sua elaboração propõe, de igual modo, uma integração, que comporta, neste caso, distintos usuários das águas que correm no município: o símbolo disposto no centro, onde se vê um pescador, de pé, empunhando um remo (com a outra das extremidades em forma de enxada) sobre uma canoa que navega em uma vagem de soja, revela uma tentativa de aliar passado e presente (futuro?), tradição e modernidade. A imagem do pescador, que empunha o instrumento de dupla função, permite inferir que se trata de uma representação do homem ligado às tradições ribeirinhas e camponesas, enquanto a vagem da soja - sem necessitar grande esforço de análise - remete ao agronegócio.

Segundo Cardoso e Almeida (2010, p. 42-43), referindo-se às comunidades tradicionais que vivem nas margens dos rios dos cerrados baianos e cuja representação na bandeira lhes cabe, "As comunidades beiradeiras resistem às mudanças radicais efetuadas pelo crescimento demográfico e econômico. Tidas como isoladas e atrasadas em relação às técnicas implantadas nos campos de cultivo agrícola, elas comandam, ainda, suas vidas com o olhar no futuro e na prática de suas tarefas comunitárias".

São, portanto, uma coletividade arredia, resistente e, pelo modo de vida que mantém, divergente em relação às transformações que o agronegócio - representado na bandeira pela vagem de soja - imprime no município desde finais da década de 1970. Assim posto, ainda que representados com justiça na bandeira, dada a sua importância na conformação de uma identidade que é sertaneja, como já visto, mas também ribeirinha, a sua aparição em pretensa convergência com o agronegócio é carente de sentido e substância.

\section{CONSIDERAÇÕES FINAIS}

Os processos de territorialização ocorrem não apenas por meio da construção material de artefatos e objetos garantidores da prevalência dos interesses de um agente frente aos demais naquilo que diz respeito à apropriação/dominação/controle de um dado espaço, mas também pela criação de normas e símbolos que, de algum modo, projetam os valores que balizam o modo de pensar e agir desses indivíduos e/ou grupos detentores da primazia de uma ação territorializadora. 
Não por outro motivo, no mais das vezes, os símbolos municipais são compostos por elementos que denotam aspectos arbitrariamente escolhidos com o intuito de enfatizar aquilo que, sob uma ótica específica, seja considerado a representação sintética de uma sociedade e território. Em outras palavras, a letra de um hino, as cores, formas e figuras empregadas na composição de uma bandeira ou brasão de armas devem ter o poder de expressar uma retórica de uma geografia local.

Em se tratando dos símbolos municipais de Barreiras, criados na década de 1990 sob um contexto de transformação dos espaços agrícolas antes dominados por atividades tradicionais em territórios crescentemente dominados pelos agentes econômicos envolvidos na moderna produção de grãos, vê-se uma forte influência dos aspectos socioeconômico, político e cultural que marcaram essa etapa de transição em sua composição.

Assim, na composição dos símbolos municipais barreirenses, recorre-se a um conjunto de elementos que, ao mesmo tempo, evocam, sob uma áurea de pretensa harmonia, o tradicional e o moderno, o poder da racionalidade econômica, aparente nas referências à agricultura de alto rendimento, e o seu contraexemplo, representado pela identidade forjada por grupos sociais que habitam as terras do atual município de Barreiras há séculos.

Neste sentido, aquilo que, por meio da bandeira e brasão municipais, se tenta denotar como uma relação harmônica, serve tão somente como cortina de fumaça sobre as contradições que permeiam a copresença, em território barreirense, da tecnosfera e psicosfera (SANTOS, 2006) representativas da modernidade e tradição existentes no município e que são acionadas por meio desses símbolos.

\section{REFERÊNCIAS}

ÁLVAREZ RODRÍGUEZ, Rafael. Diccionario de Vexilología. Madrid: Sociedad Española de Vexilología, 2003.

BARREIRAS, Câmara Municipal de. Lei Orgânica do Município de Barreiras-BA. Barreiras: Câmara Municipal de Barreiras, 2015.

BARREIRAS ganha símbolos. Jornal Nova Fronteira, Ano II, n. 31, Barreiras, p. 6, 1991.

BERG, Tiago. Território, cultura e regionalismo: aspectos geográficos em símbolos estaduais brasileiro. Dissertação de Mestrado, Programa de Pós-graduação em Geografia. Rio Claro: Universidade Estadual Paulista, 2009.

Paisagens, imagens e suas representações (geo)gráficas nas bandeiras. Espaço \& Geografia, v. 15, n. 2, Brasília, p. 311-332, 2012.

Geografia e Heráldica: lendo a representação da paisagem nos brasões de armas dos estados brasileiros. Geografia Ensino \& Pesquisa, 19 (número especial), Santa Maria, p. 123-133, 2015.
BRANDÃO, Paulo Roberto Baqueiro. Barreiras e Luís Eduardo Magalhães: uma aglomeração embrionária no Oeste Baiano? In: DIAS, P.; SANTOS, J. (Org.), Cidades médias e pequenas: contradições, mudanças e permanências nos espaços urbanos. Salvador: Superintendência de Estudos Econômicos e Sociais da Bahia, 2012, p. 183-195.

CARDOSO, Evanildo Santos; ALMEIDA, Maria Geralda. A essência do lugar e da paisagem: um olhar sobre os beiradeiros do Rio de Ondas Barreiras - Bahia. GeoNordeste, v. XXI, n. 1, Aracaju, p. 33-50, 2010.

ELIAS, Denise. Redes agroindustriais e produção do espaço urbano no Brasil agrícola. In: SILVA, J.; LIMA, L., ELIAS, D. (Org.). Panorama da Geografia brasileira 1. São Paulo: Annablume, 2006, p. 221238.

HAESBAERT, Rogerio. Dos múltiplos territórios à multiterritorialidade. In: HEIDRICH, A.; COSTA, B.; PIRES, C.; UEDA, V. (Org.). A emergência da 
multiterritorialidade. A ressignificação da relação do humano com o espaço. Canoas: Editora da Universidade Luterana do Brasil, 2008, p. 19-36.

NOGUEIRA, Sonia Patrícia Marques. Tradição $e$ inovação na identidade visual dos municípios portugueses: do brasão à marca. Dissertação de Mestrado, Departamento de Publicidade. Covilhã: Universidade da Beira Interior, 2012.

PAASI, Anssi. Territory. In: AGNEW, J.; MITCHELL, K.; TOAL, G. (Ed.), A companion to Political Geography. Oxford: Blackwell Publishing, 2003, p. 109-122.

ROCHA, Geraldo. O Rio São Francisco. Fator precípuo da existência do Brasil. São Paulo: Companhia Editora Nacional, 2004 [1940].

RODRIGUES, Suelen; FERREIRA, Darlene. 0 campo e o território nas políticas de desenvolvimento. In: FERREIRA, D.; FERREIRA, E. (Org.). Estudos agrários. Conceitos e práticas. Rio Claro: Programa de Pós-graduação em Geografia da Universidade Estadual Paulista, 2009, p. 13-28.

SANTOS, Milton. Técnica, espaço, tempo. Globalização e Meio técnico-científicoinformacional. São Paulo: Hucitec, 1994.
A natureza do espaço. Técnica e tempo. Razão e emoção. São Paulo: Editora da Universidade de São Paulo, São Paulo, 2006.

SANTOS FILHO, Milton. O processo de urbanização no Oeste Baiano. Recife: Superintendência do Desenvolvimento do Nordeste, 1989.

SAQUET, Marcos. Por uma abordagem territorial. In: SAQUET, M.; SPOSITO, E. (Org.). Território $e$ territorialidades. Teorias, processos e conflitos. São Paulo: Expressão Popular, 2009, p. 73-94.

SOUZA, Marcelo Lopes de. "Território" da divergência (e da confusão): em torno das imprecisas fronteiras de um conceito fundamental. In: SAQUET, M.; SPOSITO, E. (Org.). Território e territorialidades. Teorias, processos e conflitos. São Paulo: Expressão Popular, 2009, p. 57-72.

SOUZA, Ueliton Basílio; SANTOS, Pablo Santana; BRANDÃO, Paulo Roberto Baqueiro. Agronegócio e mudanças espaciais: um estudo de caso do espaço barreirense. Caminhos de Geografia, v. 16, n. 56, Uberlândia, p. 95-109, 2015.

THÉRY, Hervé. Heráldica e Geografia. Mercator, v. 12, n. 29, Fortaleza, p. 7-22, 2013. 